\title{
Feasibility of molecular testing in a multicenter study with geographical variation in India: Epidermal growth factor receptor mutation as a model molecular test
}

\begin{abstract}
Context: Trends in epidermal growth factor receptor (EGFR) mutation based on ethnicity assist the initial selection of targeted therapy regimen. Reported incidence of EGFR mutation in Indian NSCLC patients is variable, ranging from $22 \%$ to $51.8 \%$.

Aim and Settings and Design: This multicenter, noninterventional study evaluated the prevalence of EGFR mutation in Indian NSCLC patients, its association with patients' demographics, and for the first time used a central laboratory for molecular testing.

Subjects and Methods: Tissue samples from 252 NSCLC patients were tested at a Central Laboratory at Tata Memorial Hospital.

Statistical Analysis Used: Patient demographics, baseline characteristics including smoking status from routine examination were recorded in a single visit. Chi-square or Fisher's exact test was used for association of EGFR mutation status with gender, age, smoking status, and histological subtypes.

Results: The prevalence of EGFR mutation in Indian NSCLC patients was $23.4 \%$. Among these, $55.9 \%$ patients had mutations in exon 19 , $39 \%$ in exon 21 , and $1.7 \%$ in exon 18. The incidence of EGFR mutation was higher in females than males ( $32.5 \%$ vs. $18.9 \%$, respectively), and in $30.6 \%$ patients that had never smoked, $26.3 \%$ smokers, and $5.8 \%$ former smokers. The mean duration of transportation of tissue samples to the central laboratory was $48 \mathrm{~h}$ with an average turnaround time of 5 days for molecular testing.

Conclusions: Molecular testing at a central laboratory is a feasible option in India. Prevalence of EGFR mutation in Indian NSCLC patients was similar across western and southern centers in India. A statistically significant association between EGFR mutation and gender as well as the smoking status of the patients was observed. Majority of the patients had in-frame deletions in exon 19.
\end{abstract}

Keywords: Epidermal growth factor receptor mutation, nonsmall cell lung cancer, tyrosine kinase inhibitor, India

\section{INTRODUCTION}

Over two decades ago, molecular profiling of lung cancer led to the identification of driver mutations as oncogenic triggers in NSCLC. The incidence of epidermal growth

\begin{tabular}{|l|c|}
\hline \multicolumn{2}{|c|}{ Access this article online } \\
\hline \multirow{2}{*}{$\begin{array}{l}\text { Website: } \\
\text { www.asjo.in }\end{array}$} & Quick Response Code \\
\hline \multirow{2}{*}{$\begin{array}{l}\text { DOI: } \\
\text { 10.4103/ASJO.ASJO_104_16 }\end{array}$} & \\
&
\end{tabular}

This is an open access article distributed under the terms of the Creative Commons Attribution-NonCommercial-ShareAlike 3.0 License, which allows others to remix, tweak, and build upon the work non-commercially, as long as the author is credited and the new creations are licensed under the identical terms.

For reprints contact: reprints@medknow.com

How to cite this article: Prabhash K, Rauthan A, Rajappa S, Desai C, Mistry R, Dutt $A$, et al. Feasibility of molecular testing in a multicenter study with geographical variation in India: Epidermal growth factor receptor mutation as a model molecular test. Asian J Oncol 2017;3:39-44.
Kumar Prabhash, Amit Rauthan ${ }^{1}$, Senthil Rajappa ${ }^{2}$, Chirag Desai 3 , Rajesh Mistry 4 , Amit Dutt 5 , Anuradha Chougule, Ravi Mohan ${ }^{6}$, Pratap K Das ${ }^{7}$, RAJIV Kumar ${ }^{8}$, VANITA NORONHA, AMIt JOShI, Vijay M Patil, Binay SWarup ${ }^{\text {, Anil Kukreja9 }}$

Departments of Medical Oncology and ${ }^{8}$ Pathology, Tata Memorial Hospital, Dr. Ernest Borges Marg, ${ }^{9}$ Medical Department, Roche Products (India) Pvt. Ltd., Bandra Kurla Complex, ${ }^{4}$ Department of Oncology and Surgical Oncology, Kokilaben Dhirubhai Ambani Hospital and Medical Research Institute, Mumbai, ${ }^{5}$ Department of Medical Research, Tata Memorial Centre, Advanced Centre for Treatment, Research and Education in Cancer, Navi Mumbai, Maharashtra, ${ }^{1}$ Department of Medical Oncology, Clinical Research Center, Manipal Hospital, Bengaluru, Karnataka, ${ }^{2}$ Department of Medical Oncology, Basavatarakam Indo-American Cancer Hospital and Research Institute, Hyderabad, Telangana, ${ }^{3}$ Department of Medical Oncology, Hemato Oncology Clinic Ahmedabad Private Limited, Ahmedabad, Gujarat, ${ }^{6}$ Department of Medical Oncology, King George Hospital, Visakhapatnam, Andhra Pradesh, 'Department of Medical Oncology, Indraprastha Apollo Hospitals, New Delhi, India

Address for correspondence: Dr. Kumar Prabhash, Department of Medical Oncology, Tata Memorial Hospital, Dr. Ernest Borges Marg, Parel, Mumbai - 400 012,

Maharashtra, India.

E-mail: kumarprabhashtmh@gmail.com 
factor receptor (EGFR) mutations has been reported to differ across ethnic groups..$^{[1-6]}$ Mutations in exons 19-21 affect kinase activity which is fundamental to the activation of the receptor by autophosphorylation. Subsequently, the receptor gets blocked into a state of constitutive activation thereby signaling the cell to proliferate and resist apoptosis. The substitution at codon 858 (L858R) in exon 21 and in-frame deletions at exon 19 (del E746-A750 being the most common) are the most prevalent accounting for approximately $85 \%-90 \%$ of all EGFR mutations. ${ }^{[7,8]}$ Insertions in exon 20 and substitution at codon 719 (G719S) in exon 18 are rare, accounting for about $5 \%$ of the mutations. ${ }^{[9]}$

These deeper understandings of the molecular pathways affected by these genetic mutations have heralded an era of targeted therapy. These drugs specifically target the pathways of oncogenesis mediated by EGFR hyperactivation. EGFR tyrosine kinase inhibitors (TKIs) gefitinib, erlotinib, and afatinib specifically targeting EGFR oncogenes have demonstrated an improved progression-free survival, overall survival, response rate (RR), and quality of life as well as a better tolerability when compared with first-line chemotherapy in several phase III randomized trials..$^{[10-16]}$

EGFR mutation rate is higher in Asians, women, never smokers, and patients with adenocarcinoma subtype..$^{[14,17]}$ The incidence rate of EGFR mutation in Indian NSCLC patients reported in literature has been varied, ranging from $22 \%$ to 51.8\%. ${ }^{[18-21]}$ Limitations of sample size and clinical selection of the participants have been attributed to the overestimation of incidence rate in some of these studies. ${ }^{[22]}$ In addition, most of these studies were single-center studies. The variability of samples accorded by a multicentric trial remains undisputed and most imperative from an epidemiological aspect. To determine the prevalence of EGFR mutation across the diverse population of India, we therefore undertook the multicentric study to answer this question.

\section{SUBJECTS AND METHODS}

\section{Study design}

The present study was designed as a noninterventional, multicenter, epidemiological study. It was conducted at seven centers across India with the objective to evaluate the prevalence of EGFR mutation in NSCLC patients in India (CTRI No.: CTRI/2013/10/004077). Treatment-naive or treatment-experienced male or female patients diagnosed with NSCLC and with available tumor specimens from biopsy samples for genetic analysis were enrolled in this study. The samples were sent for EGFR testing to a Central Laboratory at Tata Memorial Hospital, Mumbai; a Tertiary Care Center in India. Patients, who in the opinion of the investigator were unable to comply with study requirements, were excluded from the study. Written informed consent to perform the EGFR mutation analysis, using their available tumor samples, was obtained from all patients prior to their inclusion in the study. The Independent Ethics Committee or Institutional Review Board of all the participating centers approved the study protocol. The study was carried out in accordance with the Declaration of Helsinki and Good Clinical and Epidemiological Practices, guidelines, and relevant applicable regulatory requirements.

This study involved a single visit to capture information of patient demographics, baseline characteristics including smoking status and histopathology from routine examination performed in accordance with current guidelines and local standard of care. This was documented in the electronic CRF. The primary outcome measure was the incidence of EGFR mutation and the secondary outcome measures included types of EGFR mutation and association of mutation status with patients' demographics and histological subtype of NSCLC.

\section{Sample size}

There was no formal sample size calculation for this study. This was an epidemiological study; hence, a sample size of 250 patients would give meaningful insight into the scientific outcomes of this study as well as evaluate the feasibility of molecular testing at a central laboratory for samples collected from multiple centers across the country.

\section{Collection of tissue samples}

The patient samples were collected in the form of formalin-fixed paraffin-embedded (FFPE) tissue blocks from all the study centers and transported in ambient temperature through a courier service to the Central Laboratory at Tata Memorial Hospital.

DNA extraction and epidermal growth factor receptor mutation analysis

DNA was extracted from the FFPE blocks of the patients for EGFR mutation analysis. Hematoxylin and eosin stained tissue blocks were initially verified to constitute $75 \%$ of the tissue mass. Six sections of this tissue, sectioned using a microtome (Leica), were deparaffinized with xylene and the DNA extraction, and EGFR mutation analysis was conducted as described by Noronha et al. ${ }^{[21]}$ The mutations studied were in-frame deletions in exon 19, an L858R point mutation in exon 21, and the G719C point mutation in exon 18.

\section{Statistical analysis}

Statistical analysis was done using SAS version 9.1.3, SAS Institute Inc., Cary, NC, USA. EGFR mutation was categorized 
as positive or negative qualitatively. Descriptive statistics were used to summarize the variables. Chi-square or Fisher's exact test was used, as appropriate, to find the association of EGFR mutation status and mutations in exon 18-21 across gender, age, smoking status, and histological subtypes as categories. The 95\% confidence interval was constructed for primary and secondary endpoints, and a value of $P<0.05$ was considered as the level of significance.

\section{RESULTS}

A total of 301 patients were screened from September 2013 to November 2014, of which, 252 patients were enrolled in the study and 49 patients were screen failures due to inadequate tissue sample. The patient and disposition chart are provided in Figure 1. Among the 252 patients, 169 (67.1\%) were male and 83 (32.9\%) were female, median age was 57 years with $186(73.8 \%)$ patients in the age group of 18-64 years. Data on their smoking status, stage of disease, and NSCLC histology are presented in Table 1.

The mean duration of transportation of tissue samples to and from the central laboratory was $48 \mathrm{~h}$, and the average turnaround time for molecular testing was 5 days.

Of the 252 patient samples analyzed, 59 (23.4\%) were EGFR mutation positive and 193 (76.6\%) were negative for EGFR mutation. EGFR mutations were identified in exon 19 in 33 (55.9\%) patients, in exon 21 in 23 (39\%) patients, and in exon 18 in 1 (1.7\%) patient [Table 2].

In terms of geographic regions, of the 198 patients from the study centers in the western part of India, 48 (24.2\%) were EGFR mutation positive and out of the fifty patients from the study centers in the southern part of India, $11(22 \%)$ were

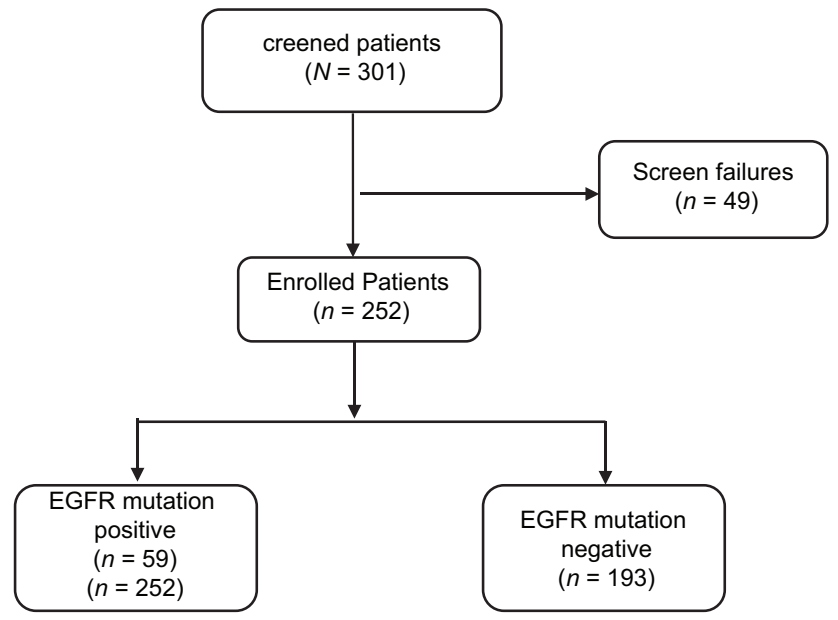

Figure 1: Patient disposition flow chart. Of the 252 patients enrolled, 59 were epidermal growth factor receptor mutation positive
EGFR mutation positive. Four patients were enrolled from the northern part of India and none of whom were mutation positive [Table 2]. There were no centers in eastern part of India.

Patients in the age category of 40-49 years had a higher incidence of EGFR mutation (31\%) as compared with other age categories. However, there was no statistically significant association between age and EGFR mutation $(P=0.6106)$. There was a statistically significant association between EGFR mutation status and gender $(P=0.0166)$ and smoking status $[P=0.0003$, Table 3].

Table 1: Patient demographic and clinical characteristics

\begin{tabular}{lc}
\hline Variables & Number of patients $(\boldsymbol{n}=\mathbf{2 5 2})$ \\
\hline Median age (years) & $57(27-86)$ \\
Age categories (years), $n(\%)$ & $186(73.8)$ \\
$18-64$ & $64(25.4)$ \\
$65-84$ & $2(0.8)$ \\
$85+$ & \\
Gender, $n(\%)$ & $169(67.1)$ \\
Male & $83(32.9)$ \\
Female & \\
Smoking status, $n(\%)$ & $19(8.1)$ \\
Smoker & $69(29.4)$ \\
Former smoker & $147(62.6)$ \\
Never smoked & \\
Disease stage, $n$ (\%) & $7(2.8)$ \\
Stage I & $9(3.6)$ \\
Stage II & $4(1.6)$ \\
Stage IIIA & $17(6.7)$ \\
Stage IIIB & $215(85.3)$ \\
Stage IV & \\
Histology of NSCLC, $n(\%)$ & $213(84.5)$ \\
Adenocarcinoma & $29(11.5)$ \\
Squamous cell carcinoma & $2(0.8)$ \\
Large cell carcinoma & $8(3.2)$ \\
Other &
\end{tabular}

NSCLC - Nonsmall-cell lung cancer

Table 2: Epidermal growth factor receptor mutation status and type

\begin{tabular}{lc}
\hline Variable & Number of patients $(\boldsymbol{n}=\mathbf{5 9})$ \\
\hline EGFR mutation status, $n(\%)$ & $59(23.4)$ \\
Positive & $193(76.6)$ \\
Negative & \\
EGFR mutation type, $n(\%)$ & $1(1.7)$ \\
Exon 18 & $33(55.9)$ \\
Exon 19 & $23(39.0)$ \\
Exon 21 & \\
Geographical region of study center, $n(\%)$ & $11(24.2)$ \\
West $(n=198)$ & $11(22)$ \\
South ( $n=50)$ & \\
\hline Western India includes two study centers in Mumbai and one in Ahmedabad, \\
southern India includes one study center in Hyderabad, one in Bengaluru, one in \\
Vishakhapatnam, and one study center in northern India (New Delhi) enrolled four \\
patients but all were EGFR negative. EGFR - Epidermal growth factor receptor
\end{tabular}


Prabhash, et al.: Feasibility of molecular testing in multicenter study in India

Table 3: Association of epidermal growth factor receptor mutation status with age, gender, and smoking status

\begin{tabular}{|c|c|c|c|c|c|}
\hline Variables & Category & $\begin{array}{c}\text { Total number of } \\
\text { patients }(n=252)\end{array}$ & $\begin{array}{c}\text { EGFR mutation } \\
\text { positive }(n=59)(\%)\end{array}$ & $\begin{array}{c}\text { EGFR mutation } \\
\text { negative }(n=193)(\%)\end{array}$ & $P$ \\
\hline \multirow[t]{7}{*}{ Age } & $20-29$ & 2 & 0 & $2(100.0)$ & $0.6106^{\wedge}$ \\
\hline & $30-39$ & 14 & $1(7.1)$ & $13(92.9)$ & \\
\hline & $40-49$ & 42 & $13(31.0)$ & $29(69.0)$ & \\
\hline & $50-59$ & 89 & $22(24.7)$ & $67(75.3)$ & \\
\hline & $60-69$ & 74 & $15(20.3)$ & $59(79.7)$ & \\
\hline & $70-79$ & 24 & $6(25.0)$ & $18(75.0)$ & \\
\hline & $80-89$ & 7 & $2(28.6)$ & $5(71.4)$ & \\
\hline \multirow[t]{3}{*}{ Gender } & Male & 169 & $32(18.9)$ & $137(81.1)$ & $0.0166^{*}$ \\
\hline & Female & 83 & $27(32.5)$ & $56(67.5)$ & \\
\hline & Total $(n)$ & 252 & $59(23.4)$ & $193(76.6)$ & \\
\hline \multirow[t]{5}{*}{ Smoking status } & Smoker & 19 & $5(26.3)$ & $14(73.7)$ & $0.0003^{*}$ \\
\hline & Former smoker & 69 & $4(5.8)$ & $65(94.2)$ & \\
\hline & Never smoked & 147 & $45(30.6)$ & $102(69.4)$ & \\
\hline & Total $(n)$ & 235 & $54(23.0)$ & $181(77.0)$ & \\
\hline & Data not available & 17 & $5(29.4)$ & $12(70.6)$ & \\
\hline \multirow[t]{6}{*}{ Pathological stage } & Stage I & 7 & $2(28.6)$ & $5(71.4)$ & $0.4765^{*}$ \\
\hline & Stage II & 9 & $4(44.4)$ & $5(55.6)$ & \\
\hline & Stage IIIA & 4 & $1(25)$ & $3(75)$ & \\
\hline & Stage IIIB & 17 & $1(5.9)$ & $16(94.1)$ & \\
\hline & Stage IV & 215 & $51(23.7)$ & $164(76.3)$ & \\
\hline & Total $(n)$ & 252 & $59(23.4)$ & $193(76.6)$ & \\
\hline \multirow[t]{4}{*}{ Histology of NSCLC } & Squamous cell carcinoma & 29 & $5(17.2)$ & $24(82.8)$ & $0.7940^{\wedge}$ \\
\hline & Adenocarcinoma & 213 & $53(24.9)$ & $160(75.1)$ & \\
\hline & Large cell carcinoma & 2 & 0 & $2(100)$ & \\
\hline & Other & 8 & $1(12.5)$ & $7(87.5)$ & \\
\hline
\end{tabular}

*Chi-square/Fisher's exact test was used appropriately to find the effect of EGFR mutation. Denominator for calculation of percentage was the total number of patients in respective category. EGFR - Epidermal growth factor receptor; NSCLC - Nonsmall-cell lung cancer; $\wedge$ - Not staticaly singnificant

Among the Stage IV disease patients, $23.7 \%$ patients were EGFR mutation positive. Due to the low number of patients in other stages, the comparative analysis of mutation status across stages of the disease was inconclusive. Adenocarcinoma patients had a higher incidence of EGFR mutation (24.9\%) as compared to squamous cell carcinoma patients $(17.2 \%)$. However, the difference was not statistically significant [Table 3].

\section{DISCUSSION}

Worldwide a growing body of literature indicates a significant benefit from TKIs in this subset of the population. In India, NSCLC patients with activating mutation of EGFR demonstrated $74 \%$ RR to oral TKI compared to $5 \%$ in patients with wild-type EGFR. ${ }^{[21]}$ Identification of patterns in population genetics of NSCLC patients across different ethnicities will assist oncologists in prescribing the optimum treatment regimen.

The two unique characteristics of our study were the multicenter design and the use of a central laboratory. The centers were selected from various parts of India for this study to ensure representation from different regions of the country. A pan-India survey conducted to deduce the pattern of EGFR mutation testing across different tertiary care centers reported significant differences between centers having in-house testing facility compared to centers that outsourced the testing. ${ }^{|23|}$ One of the potential shortcomings of a multicenter design are the minor differences in execution of laboratory methodologies while following the same protocol. Therefore, to overcome this shortcoming, the samples obtained from various centers across the country were analyzed at a Central Laboratory, a Tertiary Care Center in India. To the best of our knowledge, this is the first time a central laboratory was used in an epidemiological study for EGFR mutation status in India. This study demonstrated the successful execution of molecular testing at a central laboratory for EGFR mutation status. The FFPE blocks were transported from the center to the central laboratory within $48 \mathrm{~h}$ and the average turn-around time for molecular testing was 5 days. This was significantly lower than the average 15-17 days reported in majority of the patients in the Indian Tertiary Care Centers and the PIONEER study. ${ }^{[24,25]}$ This turnaround time for molecular testing at a central laboratory can assure 
timely initiation of optimum treatment for patients as well as extend the benefits of targeted therapy to patients in tier two cities in India which may not have such testing facilities.

An important observation was the inadequacy of tissue samples in 49 out of 301 patients screened, which prevented molecular testing. This underlines an inherent problem of tissue biopsy in procurement of tissue samples and the limitations of tumor analyses. Liquid biopsy, a noninvasive method which assesses the genetic makeup of a tumor through a biofluid sample, has the potential to help clinicians screen for disease as well as monitor treatment response and resistance mechanisms in the tumor. ${ }^{[26]}$

The results of our study are in line with the global trend with the incidence of EGFR mutation higher in females (32.5\%), nonsmokers (30.6\%), adenocarcinoma (24.9\%), and Stage IV disease (23.7\%). Chougule et al. reported the prevalence (23.2\%) of EGFR mutation in a sample size of 907 patients. ${ }^{[22]}$ The frequency of EGFR mutation in exon 19 (55.9\%) in our study was also similar to $50 \%$ reported by Chougule et al..$^{[22]}$ but lower than $61.3 \%$ reported by Prabhakar et al. ${ }^{[27]}$ In this study, 29 patients had squamous cell carcinoma of which $17.2 \%$ were EGFR mutation positive. In reported literature, EGFR mutation positivity rate in the Asian population ranges from $0 \%$ to $20.5 \% .{ }^{[28-30]}$ It will be important to investigate this finding further.

Similar to the overall incidence rate observed in India, the regional incidence rate of EGFR mutation was comparable between the western centers $(24.2 \%)$ and the southern centers $(22 \%)$. This was in contrast to the higher incidence of EGFR mutation (39.6\% and 68\%) reported in southern India. ${ }^{[19,31]}$

In-frame deletion in exon 19 was predominant (55.9\%) in our study similar to observed in other Indian studies which reported an incidence of $50 \%-74 \%$. Similarly, incidence of missense mutation in exon 21 was 39\% in our study as compared to $25 \%-42 \%$ reported in previous studies in India. ${ }^{[20,22]}$ Tumors expressing an exon 19 mutant EGFR isoform have been reported to exhibit better TKI response ( $86 \%$ vs. $67 \% ; P=0.171$ ), and improved survival has been compared with patients whose tumors expressed an exon 21 mutation.

One of the limitations of this study was the retrospective design for data collection. The data on the treatment outcomes were either not available or inadequately captured during the retrospective data collection. A prospective study will allow one to follow the patient's response to treatment and thereby evaluate its relationship with their mutation status. Another shortcoming was the lack of a study center in the eastern part of India and limited enrollment in the northern India study center.

Molecular testing at a central laboratory, with an average turn-around time of 5 days, is a feasible option in India. The overall prevalence of EGFR mutation in Indian NSCLC patients was $23.4 \%$ with a similar incidence across western and southern centers in India. EGFR mutation was predominant in females, never-smokers, adenocarcinoma, and disease Stage IV patients. A statistically significant association between EGFR mutation and gender as well as the smoking status of the patients was observed. Majority of the patients had in-frame deletions in exon 19.

\section{CONCLUSIONS}

Molecular testing at a central laboratory is a feasible option in India. Prevalence of EGFR mutation in Indian NSCLC patients was similar across western and southern centers in India. A statistically significant association between EGFR mutation and gender as well as the smoking status of the patients was observed. Majority of the patients had in-frame deletions in exon 19.

\section{Acknowledgment}

The authors would like to acknowledge the contribution of the following from of Roche Products (India) Pvt.: Dr. Balaji Ugile for his valuable inputs on the draft; Anant Dethe for data acquisition and Priyanka Bhattacharya for medical writing support.

Financial support and sponsorship

This study was funded by Roche Products (India) Pvt. Ltd.

\section{Conflicts of interest}

The authors would like to disclose that Dr. Amit Rauthan, Dr. Rajesh Mistry, and Dr. P.K. Das are Advisory Board Members for Roche Products (India) Pvt. Ltd. The remaining authors have no conflict of interest.

\section{REFERENCES}

1. Lynch TJ, Bell DW, Sordella R, Gurubhagavatula S, Okimoto RA, Brannigan $\mathrm{BW}$, et al. Activating mutations in the epidermal growth factor receptor underlying responsiveness of non-small-cell lung cancer to gefitinib. N Engl J Med 2004;350:2129-39.

2. Dogan S, Shen R, Ang DC, Johnson ML, D'Angelo SP, Paik PK, et al. Molecular epidemiology of EGFR and KRAS mutations in 3,026 lung adenocarcinomas: Higher susceptibility of women to smoking-related KRAS-mutant cancers. Clin Cancer Res 2012;18:6169-77.

3. Cortes-Funes H, Gomez C, Rosell R, Valero P, Garcia-Giron C, Velasco A, et al. Epidermal growth factor receptor activating mutations 
in Spanish gefitinib-treated non-small-cell lung cancer patients. Ann Oncol 2005;16:1081-6.

4. Reinersman JM, Johnson ML, Riely GJ, Chitale DA, Nicastri AD, Soff GA, et al. Frequency of EGFR and KRAS mutations in lung adenocarcinomas in African Americans. J Thorac Oncol 2011;6:28-31.

5. Wu YL, Zhong WZ, Li LY, Zhang XT, Zhang L, Zhou CC, et al. Epidermal growth factor receptor mutations and their correlation with gefitinib therapy in patients with non-small cell lung cancer: A meta-analysis based on updated individual patient data from six medical centers in mainland China. J Thorac Oncol 2007;2:430-9.

6. Yang PC, Shi Y, Au JS, Srinivasan S, Cornelio GH, Tsai CM, et al. Molecular epidemiological prospective study of EGFR mutations from Asian patients (pts) with advanced lung adenocarcinoma. J Thorac Oncol 2014;9:154-62. Doi: 10.1097 /JTO.0000000000000033.

7. Kawahara A, Yamamoto C, Nakashima K, Azuma K, Hattori S, Kashihara $\mathrm{M}$, et al. Molecular diagnosis of activating EGFR mutations in non-small cell lung cancer using mutation-specific antibodies for immunohistochemical analysis. Clin Cancer Res 2010;16:3163-70.

8. Seo AN, Park TI, Jin Y, Sun PL, Kim H, Chang H, et al. Novel EGFR mutation-specific antibodies for lung adenocarcinoma: Highly specific but not sensitive detection of an E746_A750 deletion in exon 19 and an L858R mutation in exon 21 by immunohistochemistry. Lung Cancer 2014;83:316-23.

9. Beau-Faller M, Prim N, Ruppert AM, Nanni-Metéllus I, Lacave R, Lacroix L, et al. Rare EGFR exon 18 and exon 20 mutations in non-small-cell lung cancer on 10117 patients: A multicentre observational study by the French ERMETIC-IFCT network. Ann Oncol 2014;25:126-31.

10. Douillard JY, Shepherd FA, Hirsh V, Mok T, Socinski MA, Gervais R, et al. Molecular predictors of outcome with gefitinib and docetaxel in previously treated non-small-cell lung cancer: Data from the randomized phase III INTEREST trial. J Clin Oncol 2010;28:744-52.

11. Shepherd FA, Rodrigues Pereira J, Ciuleanu T, Tan EH, Hirsh V, Thongprasert $\mathrm{S}$, et al. Erlotinib in previously treated non-small-cell lung cancer. N Engl J Med 2005;353:123-32.

12. Zhou C, Wu YL, Chen G, Feng J, Liu XQ, Wang C, et al. Erlotinib versus chemotherapy as first-line treatment for patients with advanced EGFR mutation-positive non-small-cell lung cancer (OPTIMAL, CTONG-0802): A multicentre, open-label, randomised, phase 3 study. Lancet Oncol 2011;12:735-42.

13. Sequist LV, Yang JC, Yamamoto N, O’Byrne K, Hirsh V, Mok T, et al. Phase III study of afatinib or cisplatin plus pemetrexed in patients with metastatic lung adenocarcinoma with EGFR mutations. J Clin Oncol 2013;31:3327-34.

14. Wu YL, Zhou C, Hu CP, Feng J, Lu S, Huang Y, et al. Afatinib versus cisplatin plus gemcitabine for first-line treatment of Asian patients with advanced non-small-cell lung cancer harbouring EGFR mutations (LUX-Lung 6): An open-label, randomised phase 3 trial. Lancet Oncol 2014;15:213-22.

15. Neal JW. The SATURN trial: The value of maintenance erlotinib in patients with non-small-cell lung cancer. Future Oncol 2010;6:1827-32.

16. Mok TS, Wu YL, Thongprasert S, Yang CH, Chu DT, Saijo N, et al. Gefitinib or carboplatin-paclitaxel in pulmonary adenocarcinoma. N Engl J Med 2009;361:947-57.

17. Reck M, Popat S, Reinmuth N, De Ruysscher D, Kerr KM, Peters S; ESMO Guidelines Working Group. Metastatic non-small-cell lung cancer (NSCLC): ESMO Clinical Practice Guidelines for diagnosis, treatment and follow-up. Ann Oncol 2014;25 Suppl 3:iii27-39.

18. Sahoo R, Harini VV, Babu VC, Patil Okaly GV, Rao S, Nargund A, et al. Screening for EGFR mutations in lung cancer, a report from India. Lung Cancer 2011;73:316-9.

19. Pungliya M, Sachin M, Soumittra N, Shekar P, Shyam A. A study of incidence of EGFR mutations in non-smoker adenocarcinoma of the lung: Disparity between north and South Indian patients. J Cancer Ther Res 2014;3:4.

20. Pungliya M, Sachin M, Soumittra N, Shekar P, Shyam A. A study of incidence of EGFR mutations in non-smoker adenocarcinoma of the lung: disparity between north and south indian patients. J Cancer Ther Res 2014;3:4. Available from: http://dx.doi.org/10.7243/2049-7962-3-4.

21. Noronha V, Prabhash K, Thavamani A, Chougule A, Purandare N, Joshi A, et al. EGFR mutations in Indian lung cancer patients: Clinical correlation and outcome to EGFR targeted therapy. PLoS One 2013;8:e61561.

22. Chougule A, Prabhash K, Noronha V, Joshi A, Thavamani A, Chandrani P, et al. Frequency of EGFR mutations in 907 lung adenocarcioma patients of Indian ethnicity. PLoS One 2013;8:e76164.

23. Prabhash K, Parikh PM, Noronha V, Joshi A, Rajappa SJ, Bondarde SA, et al. Patterns of EGFR testing for lung cancer among tertiary care centers in India. J Clin Oncol 2015;33. DOI: 10.1200/jco.2015.33.15_suppl. e19114.

24. Shi Y, Au JS, Thongprasert S, Srinivasan S, Tsai CM, Khoa MT, et al. A prospective, molecular epidemiology study of EGFR mutations in Asian patients with advanced non-small-cell lung cancer of adenocarcinoma histology (PIONEER). J Thorac Oncol 2014;9:154-62.

25. Brock G, Castellanos-Rizaldos E, Hu L, Coticchia C, Skog J. Liquid biopsy for cancer screening, patient stratification and monitoring. Transl Cancer Res 2015;4:280-90.

26. Das BR, Bhaumik S, Ahmad F, Mandsaurwala A, Satam H. Molecular spectrum of somatic EGFR and KRAS gene mutations in non small cell lung carcinoma: Determination of frequency, distribution pattern and identification of novel variations in Indian patients. Pathol Oncol Res 2015;21:675-87.

27. Prabhakar CN. Epidermal growth factor receptor in non-small cell lung cancer. Transl Lung Cancer Res 2015;4:110-8.

28. Zhang Q, Zhu L, Zhang J. Epidermal growth factor receptor gene mutation status in pure squamous-cell lung cancer in Chinese patients. BMC Cancer 2015; 15:88.

29. Pan SH, Su KY, Spiessens B, Kusuma N, Delahaye NF, Gruselle O, et al. Gene expression of MAGE-A and PRAME tumor antigens and EGFR mutational status in Taiwanese non-small cell lung cancer patients. Asia Pac J Clin Oncol 2016. Doi: 10.1111/ajco.12586. [Epub ahead of print].

30. Bhatt AD, Pai R, Rebekah G, Nehru GA, Dhananjayan S, Samuel A, et al. Clinicopathologic features of non-small cell lung cancer in India and correlation with epidermal growth factor receptor mutational status. Indian J Cancer 2013;50:94-101.

31. Cohen V, Agulnik JS, Ang C, Kasymjanova G, Batist G, Small D, et al. Epidermal growth factor receptor mutations detected by denaturing high-performance liquid chromatography in nonsmall cell lung cancer: Impact on response to therapy with epidermal growth factor receptor-tyrosine kinase inhibitors. Cancer 2010;116:4309-17. 